doi: 10.32620/oikit.2021.91.06

УДК 539.401:539.23:620.3

О. В. Шорінов

\title{
Аналіз існуючих моделей виникнення напружень в тонких плівках і покриттях
}

\author{
Національний аерокосмічний університет ім. М.Є. Жуковського \\ "Харківський авіаційний інститут»
}

\begin{abstract}
Проведено аналіз існуючих моделей виникнення напружень у тонких плівках і покриттях. Напруження при досягненні певних критичних значень можуть призводити до появи в них дефектів, тріщин, відшарування їх від підкладки тощо. Проблема прогнозування і керування знаком і величиною напружень системи покриття-підкладка $€$ актуальною незалежно від методу отримання покриттів і тонких плівок, які знайшли застосування майже у всіх галузях промисловості: оптиці, машинобудуванні, вимірювальній техніці, медицині, мікро- та наноелектроніці тощо. Дослідження нових перспективних методів формування наноструктур, наприклад отримання нанодротів в умовах плазмового середовища, потребує наявності достатньої теоретичної бази при вирішенні питань зародження й розвинення напружень. Причинами виникнення напружень у тонких плівках і покриттях можуть бути: хімічні реакції, фазові перетворення, включення i домішки, бомбардування частинками (внутрішні напруження в процесі зростання покриттів); зміна температур (термічні напруження внаслідок різних значень коефіцієнтів термічного розширення матеріалів покриттів і підкладки, можуть розвиватися після завершення процесу напилювання i охолодження системи покриття-підкладка); десормація системи покриття-підкладка тощо. Моделі виникнення напружень можна умовно поділити на такі групи: напруження, що виникають на межі поділу покриттяпідкладка, в середині покриття, та на межі поділу покриття-навколишнє середовище. В роботі також наведено методики вимірювання напружень у тонких плівках і покриттях. За одержаними результатами можна зробити висновок, що існуючі моделі виникнення напружень як в процесі зростання покриттів і плівок, так і напружень, що виникають під дією зовнішніх сил, на жаль, не дозволяють зрозуміти їх комплексного впливу на напружено-деформований стан системи покриття-підкладка та потребують подальшого розвитку і уточнення. Важливими також є питання релаксації напружень для отримання нових структур і певних властивостей покриттів. Розроблення інструментів керування напруженнями можна розглядати як один із шляхів підвищення ресурсу виробів 3 покриттями й тонкими плівками.
\end{abstract}

Ключові слова: напружено-деформований стан, напруження, нанотехнологія, тонкі плівки і покриття, руйнування покриттів.

\section{Вступ}

Руйнування тонких плівок і покриттів є однією з основних причин виходу 3 ладу деталей і виробів, на які вони нанесені, що спричинено спільною дією внутрішніх механічних напружень (далі - напружень), напружень, що виникають у процесі їх фрормування (залишкових), і напружень, що зв'являються під час експлуатації. Руйнування плівок і покриттів може виявлятися у вигляді утворення тріщин під дією розтягальних напружень [1, 2] або відшарування, викривлення або спучування при стискаючих напруженнях [3-6]. Залишкові напруження, що виникають у покриттях і плівках, впливають майже на всі основні експлуатаційні характеристики деталей. Крім можливості розвитку тріщин і відшарувань, залишкові напруження впливають на адгезійну й когезійну, статичну і багатоциклову міцності, зносостійкість, термостійкість тощо. 
У той же час напруження можуть позитивно впливати на фрізичні властивості тонких шарів і наноструктур, наприклад, електропровідність [7], діелектричну проникність [8], п'єзоелектричність, магнітну анізотропію та магнітопружний зв'язок $[9,10]$ або збільшення рухливості носіїв заряду в напівпровідниках на основі кремнію [11].

Вуглецеві та оксидні наноструктури різноманітної структури й властивостей $€$ перспективними матеріалами для використання в наноелектроніці та інших галузях промисловості. Наноструктури на основі кремнію розглядаються як потенційні матеріали для виробництва наступного покоління анодів літій-іонних акумуляторів завдяки їх надвисоким питомим потужностям [12-14]. Вертикально-орієнтовані структури графену завдяки їх властивостям можуть бути застосовані для акумулювання та зберігання електрохімічної енергії (у високопродуктивних суперконденсаторах, каталізаторах паливних елементів тощо) [15, 16]. При виготовлені сучасних напівпровідників, польових транзисторів, датчиків широко застосовуються оксидні наноструктури, властивості яких значною мірою залежать від методів і умов їх формування [17-19]. Процес зростання оксидних і вуглецевих шарів і структур супроводжується адсорбцією атомів газів [20, 21], що призводить до розвинення напружень у середині наноплівок.

Таким чином, розуміння природи виникнення напружень у тонких плівках і покриттях, а також можливість керування напружено-деформованим станом системи покриття-підкладка $\epsilon$ актуальним завданням, оскільки це безпосередньо впливає на фрормування, обробку і термін служби нових матеріалів і виробів. Розвиток теоретичної бази прогнозування та регулювання значень і знака напружень, що виникають при фрормуванні наноструктур в умовах плазмового середовища, дозволить доповнити існуючі моделі отримання таких структур $[22,23]$ з метою подальшого дослідження плазмових методів вирощування наноструктур.

\section{Основний матеріал}

\section{1. Причини виникнення напружень}

Причинами виникнення і розвинення напружень у покриттях і тонких плівках можуть бути [24]:

1) напруження, пов'язані зі зростанням покриттів і плівок. У цьому випадку необхідно розрізняти внутрішні напруження, обумовлені збільшенням покриття, і напруження, що спричинені геометричними характеристиками поверхні. Зростання внутрішніх напружень відбувається внаслідок хімічних реакцій, фазових перетворень, бомбардувань частинками тощо;

2) термічні напруження, що з'являються у результаті зміни температур і різних коефіцієнтів термічного розширення матеріалів покриття й підкладки;

3) зовнішні напруження, що виникають внаслідок деформації системи покриття-підкладка.

У загальному випадку розподіл напружень між плівкою та підкладкою є складним і неоднорідним, хоча деякі спрощення дозволяють зрозуміти характер їх розподілу. На рис. 1 схематично зображено ідеальний розподіл напружень у поперечному перерізі гомогенної плівки та вільно встановленої підкладки подалі від краю [25]. 
Відкриті інформаційні та комп'ютерні інтегровані технології, № 91, 2021

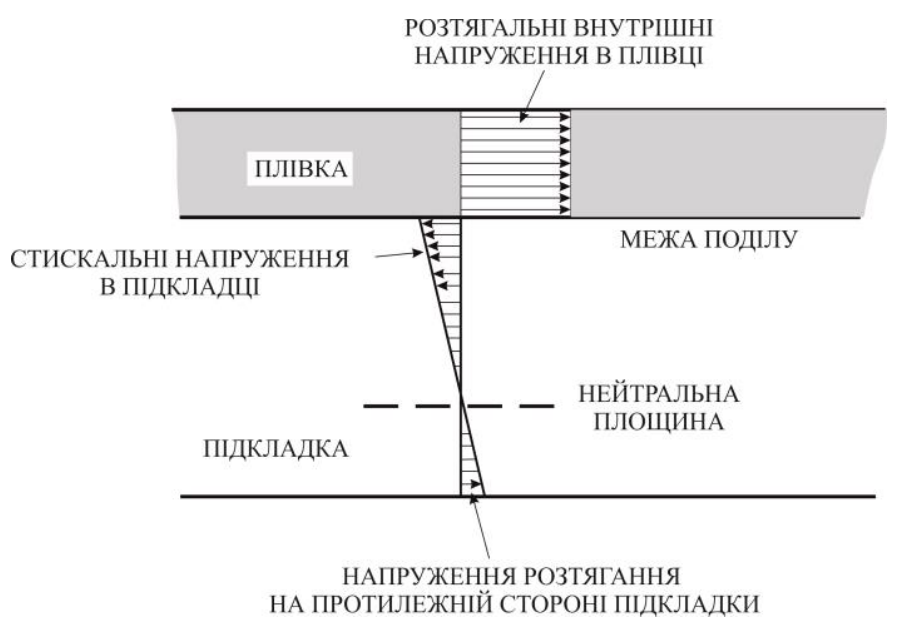

Рис. 1. Розподіл напружень у поперечному перерізі плівки та підкладки

Розподіл напружень визначається вимогами рівності нулю сумарних нормальних сил і згинальних моментів по всьому поперечному перерізі. Перша вимога означає, що в підкладці мають фрормуватися напруження протилежного знака, тому на поверхні напруження мають протилежний знак. Друга вимога означає, що підкладка має зігнутися, щоб компенсувати згинальний момент під дією плівки на одній з її поверхонь. Тому напруження в підкладці мають змінювати знак, як показано на рис. 1. Якщо товщина плівки значно менше товщини підкладки (наноплівки), то напруження в підкладці становлять лише малу частку напружень у плівці. У таких випадках можна знехтувати вигином підкладки. Внутрішні напруження мають дорівнювати нулю на вільному кінці плівки (рис. 2) [25]. Зазвичай, внутрішні напруження відносно рівномірно розподілені по товщині плівки (як показано на рис. 1). Дотичні напруження на межі поділу пропорційні товщині плівки і градієнту внутрішніх напружень уздовж межі [26], тому дотичні напруження є максимальними на краю плівки.

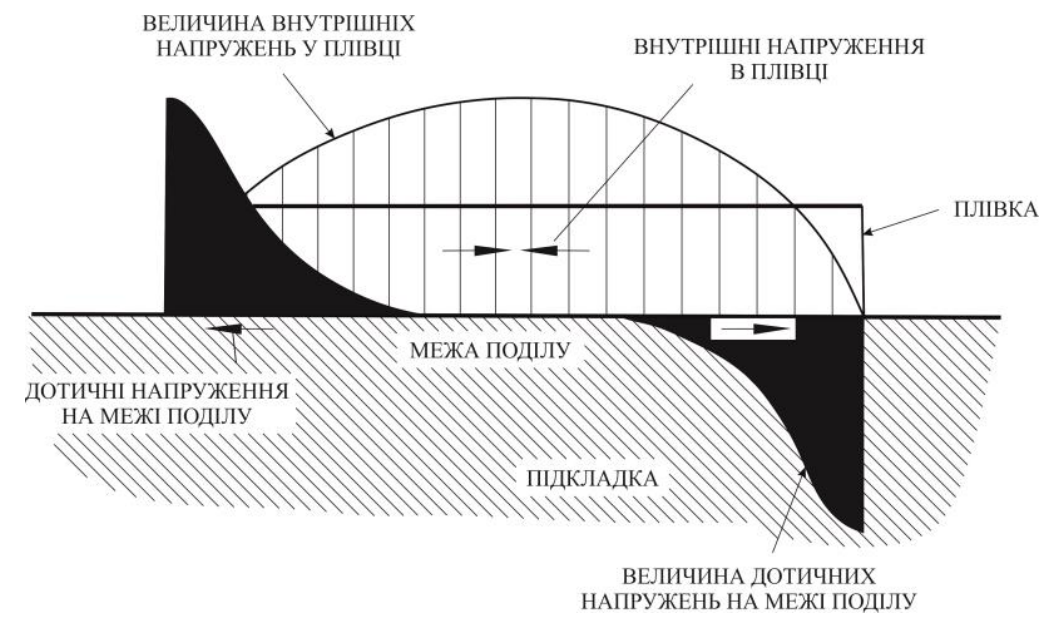

Рис. 2. Розподіл дотичних напружень на межі поділу плівка-підкладка

\section{1. Внутрішні напруження, пов'язані зі зростанням покриттів}

Модель, що пов'язує межі зерен з формуванням напружень у тонких плівках, вперше була запропонована в роботі [27]. Модель основана на тому, що із зростанням плівки і проходженням іi через морфологічні стадії (ізольовані атомні кластери, центри кристалізації, островкова плівка, суцільна плівка), 
міжатомні сили тяжіння, що діють у зазорах між сусідніми зернами, призводять до пружної деформації меж зерен. Така деформація компенсується розтягальними силами, що діють у середині зерен, і $є$ наслідком адгезії плівки до підкладки. Середнє значення зміни положення атомів межі зерен через примусову релаксацію $\Delta$ має вигляд

$$
\Delta \square \frac{a r-r^{2} / 2}{2 a-r},
$$

де а - стала величина гратки об'ємного матеріалу;

$r$ - відстань максимального наближення, що дорівнює сумі іонних радіусів, $r=2 r$, що було отримано в роботі [28] з використанням потенціалу взаємодії двох атомів. Уздовж меж зерен формуються локальні області стиснення і розтягування, але результуюче напруження є розтягальними. рівняння

Внутрішні напруження в плівці згідно з цією моделлю можна знайти 3

$$
\sigma \square \frac{E \Delta}{(1-v) d} \rho,
$$

де $v$ - коефіцієнт Пуассона;

$\rho$ - щільність упаковки.

Таким чином, для розрахунку напружень необхідно мати інформацію про кінцевий розмір зерна і пружні властивості.

Однією з причин виникнення розтягальних напружень у плівках і покриттях можуть бути дефекти (пори), які розвиваються у результаті рекристалізації та перебудови структури. Якщо самодифузія матеріалу покриття досить велика, то під час і після осадження можуть відбуватися процеси рекристалізації [29]. При цьому всі види дефектів (межі зерен, пори, точкові дефекти тощо) усуваються, що може призвести до ущільнення плівки. В роботі [30] запропоновано, що підсумкове ущільнення плівки впливає на розтягальну складову напружень:

$$
\sigma_{\text {recr }}=\frac{2 E}{1-v} \Delta v_{e x}\left(\frac{1}{D_{0}}-\frac{1}{D}\right) .
$$

Слід зауважити, що в запропонованій моделі не враховано внесок напружень, пов'язаних з релаксацією напружених ділянок через рекристалізацію. Залежно від знака деформації це можуть бути розтягальні напруження (наприклад, через наявність нерівноважних малокутових меж зерен) або стискальні (внаслідок капілярних явищ (напружень)). Подальшим розвитком отриманих результатів $€$ робота [31], в якій було наведено рівняння швидкості формування напружень, а також розрахунок напружень під час відпалу.

На розвиток внутрішніх напружень, що виникають у процесі нанесення тонких плівок і покриттів, впливають точкові дефекти. Одним із важливих механізмів розвитку напружень у плівках, отриманих методом розпилювання, $\epsilon$ так званий «атомний наклеп» (англ. atomic peening) [32]. Оскільки атоми, що розпилюються, мають високу кінетичну енергію, то при зіткненні зі зростаючою плівкою частина енергії може поглинатися в ії̈ поверхневий шар, в міжвузля кристалічної гратки. Це призводить до дисторсії кристалічної решітки і надлишкового ущільнення плівки. Як наслідок у ній виникають стискальні 
напруження, величина яких прямо пропорційна молярному об'єму та біаксиальному модулю пружності плівки [33].

Пізніше було проведено кількісне моделювання цього механізму [34]. Воно основане на теорії лінійного каскаду прямих зіткнень «переданого розпилення», запропонованого в роботі [35]. За допомогою рентгенівської дифракції отримано експериментальне підтвердження зміни кристалічних грат $[36,37]$. На основі цих припущень одержано рівняння розрахунку стискальних напружень у плівці:

$$
\sigma_{f}=k \Phi \sqrt{E_{p}} \frac{E M}{(1-v) D},
$$

де $k$ - множник, що містить число Авогадро та інші числові константи;

$Ф$ - потік іонів;

$E_{p}$ - енергія частинки;

E- модуль Юнга;

$v$ - коефіцієнт Пуассона;

$M$ - атомна маса частинки;

$D$ - щільність мішені.

Разом з атомами матеріалу, що розпилюється, в міжвузля кристалічних грат можуть потрапляти і домішкові атоми та іони, наприклад іони інертного газу, що використовуються для бомбардування мішені [38]. У моделях механізму розвитку напружень при імплантації атомів та іонів напилену плівку розглядають як матрицю, що містить введені частинки. В цьому випадку напружено-деформований стан плівки являє собою комбінацію гідростатичних напружень, обумовлених безпосередньо утворенням дефекту, і біаксиальних напружень, спричинених обмеженнями змін розмірів плівок, які на них накладає підкладка [39-41].

Інший тип точкових дефектів - вакансії - також може бути джерелом виникнення внутрішніх напружень у тонких плівках. Оскільки плівки і покриття осідають у високонерівновісних умовах, то вони містять велику кількість вакансій. Релаксаційні процеси, що протікають як під час осадження плівок, так і після закінчення цього, приводять до впорядкування їх структури, зокрема до анігіляції вакансій. В результаті виникають внутрішні напружень, знак і величина яких залежать від парціального молярного об'єму вакансій, а також від місця розташування анігіляції [42].

Внутрішні напруження в плівках і покриттях також можуть виникати внаслідок фазових перетворень, що відбуваються всередині них у процесі осадження, утворення нових фаз, а також за наявності домішок. Це можуть бути реакції, обумовлені взаємною дифузією атомів плівки і підкладки або дифузією між різними шарами в багатошарових структурах [43-45]. Крім того, можливими $\epsilon$ хімічні реакції атомів плівки 3 молекулами залишкових газів, або 3 потрапившими домішковими атомами [46].

\section{2. Напруження, що розвиваються в тонкоплівкових структурах при зовнішніх впливах}

Значний внесок у загальний рівень напружень у тонких плівках і покриттях роблять термічні напруження. Вони розглядаються як зовнішні, оскільки спричинені змінами температури, що відбуваються зазвичай після закінчення процесу осадження плівок. Крім того, термічні напруження можуть розвиватися 
при термічному обробленні плівок після їх нанесення, а також внаслідок зміни температури в процесі експлуатації тонких плівок і покриттів.

Причиною розвитку напружень в тонкоплівкових структурах при зміні температури $€$ різниця коефіцієнтів термічного розширення (КTР) плівки і підкладки. У випадку оксидних і керамічних покриттів, нанесених на металеву підкладку, КТР кераміки значно нижче, ніж КТР металу. При охолодженні в таких плівках і покриттях розвиваються стискальні напруження, а при нагріванні розтягальні [47].

Якщо система плівка-підкладка охолоджується або нагрівається при температурі від $\mathrm{T}_{1}$ до $\mathrm{T}_{2}$, то біаксіальна деформація плівки, що розвивається при цій зміні температур, визначається так:

$$
\varepsilon=-\left(\alpha_{f}-\alpha_{s}\right)\left(T_{2}-T_{1}\right)=-\Delta \alpha \Delta T
$$

де $\alpha_{f}$ i $\alpha_{s}-$ КТР матеріалів плівки і підкладки відповідно.

Якщо температура змінюється в процесі осадження плівки, то різні шари плівки будуть сприймати різну деформацію. При цьому середню біаксіальну деформацію можна розраховувати за допомогою співвідношення [42]

$$
\varepsilon \approx-\Delta \alpha\left(T_{2}-\frac{1}{h_{f}} \int_{0}^{h} T(z) d z\right),
$$

де $h_{f}$ - товщина плівки;

$d z$ - приріст її товщини.

Оскільки біаксіальні напруження пов'язані з деформацією як

$$
\sigma=\frac{E_{f}}{1-v_{f}} \varepsilon,
$$

то термічні напруження прямо пропорційні зміні температури:

$$
\sigma=-\frac{E_{f}}{\left(1-v_{f}\right)} \Delta \alpha \Delta T
$$

Значний вплив на розвиток напружень в провідникових плівках мають процеси електроміграціі. Згідно з розрахунками, виконаними в роботі [48], після того, як величина таких напружень досягає деякого граничного значення $\left(\sigma_{t}^{ \pm}\right)$, починається їх релаксація. Стискальні напруження (при $\sigma>\sigma_{t}^{+}$) сприяють зростанню здутості на поверхні плівки, а розтягальні напруження (при $\sigma>\sigma_{t}^{-}$) призводять до утворення порожнин.

Істотний вплив на розвиток напружень у тонких плівках мають ефекти, пов'язані 3 електромагнітним полем. Перш за все до них належать п'єзоелектричний ефект [49-51], електро- [52] і магнітострикції [53, 54].

Під час зберігання і експлуатації в тонкоплівкових структурах під дією зовнішніх чинників можуть відбуватися хімічні і структурні зміни, які, як і в процесі збільшення плівок, призводять до виникнення механічних напружень. Так було виявлено, що плівки можуть абсорбувати з навколишнього повітря значну кількість вологи, при цьому в них розвиваються значні стискальні напруження [55]. Нагрівання таких плівок, навпаки, спричиняє випаровування 3 них вологи та виникнення розтягальних напружень.

Слід додати, що тонкі плівки і покриття в процесі експлуатації можуть безпосередньо піддаватися різним механічним впливам, які призводять до розвитку в них напружень. Наприклад, гнучкі тонкоплівкові структури, що мають 
великі перспективи використання, в процесі експлуатації сприймають багаторазову згинальну деформацію, що призводить до розвитку в них неоднорідно розподілених градієнтів механічних напружень $[56,57]$.

\section{2. Методи вимірювання напружень у тонких плівках і покриттях}

На сьогоднішній день не існує методів прямого вимірювання механічних напружень, що діють всередині плівки. Напруження визначаються побічно: проводиться вимірювання переміщень, що виникають під дією напружень, потім - перерахунок переміщень в напруження за відповідними фрормулами.

Існуючі методи визначення напружень у тонких плівках можна поділити за типом фрізичного явища. Вибір відповідного методу може залежати від багатьох чинників і потреб дослідження: in situ (вимірювання в процесі нанесення покриття) або ex situ (вимірювання після нанесення покриття), матеріалу підкладки, типу структури плівка-підкладка і т.д. Найбільш широко використовуються два основні методи для визначення напружень у тонких плівках. Перший метод основано на вимірюванні кривизни підкладки, яка згинається під дією напружень у плівці, другий - на безпосередньому вимірюванні пружної деформації в плівці за допомогою рентгенівської дифракції. У першому випадку для визначення напружень у плівці необхідно знати пружні властивості підкладки, а в другому - пружні властивості матеріалу плівки.

\section{1. Метод визначення напружень на основі вимірювання радіуса кривизни підкладки}

Найбільш поширені методи визначення напружень у тонких плівках, отриманих на поверхні підкладки у вигляді кола або балки (тонкої пластини), основані на вимірюванні деформації підкладки. Вперше визначення напружень у тонких плівках шляхом розрахунку кривизни підкладки було виконано в роботі [58]. Для розрахунку напружень використано формулу, що пов'язує напруження в плівці $\sigma_{f}$ і радіус кривизни підкладки $\mathrm{R}_{\mathrm{s}}$ :

$$
\sigma_{f}=\frac{E_{s} t_{s}^{2}}{6 R_{s} t_{f}},
$$

де $E_{s}$ - модуль пружності підкладки;

$t_{s}$ - товщина підкладки;

$R$ - радіус кривизни підкладки;

$t_{f}$ - товщина плівки.

До основних недоліків формули слід віднести:

- формула використовується у випадку, коли плівка покриває всю поверхню підкладки;

- усвідомлення, що напруження в плівці одновісні, що для ізотропних підкладок не є вірним - напруження двовісні. Коректну фрорму рівняння, таким чином, у цьому випадку можна записати у вигляді [59]

$$
\sigma_{f}=\frac{E_{s} t_{s}^{2}}{6\left(1-v_{s}\right) R_{s} t_{f}},
$$

де $v_{s}$ - коефіцієнт Пуассона підкладки.

Частіше за все в літературі можна зустріти дві конфігурації плівкипідкладки для визначення напружень: у вигляді диска та у вигляді балки 
(пластини). При використанні методу згинання консольної балки плівку осаджують на одну з поверхонь консольно закріпленої балки. Кривизну балки знаходять шляхом вимірювання відхилення одного з її кінців, в той час як інший кінець закріплений, або за вигином середини балки у випадку закріплення обох іï кінців. При цьому питому силу S, рівномірно розподілену по ширині пластинки, визначають через напруження і товщину в плівці:

$$
S=\sigma_{f} d_{f}=\frac{\delta E_{s} d_{s}^{2}}{3 l^{2}\left(1-v_{s}\right)} .
$$

Визначення радіуса кривизни підкладки виконують за допомогою датчиків: оптичних [60-62] і ємнісних [63, 64]; методом витравлювання підкладки [65]; механічними [66], електромеханічними [67] або магнітними методами вимушеного повернення зразка в початковий стан $[68,69]$. Найбільш чутливими методами, що дозволяють проводити вимірювання безпосередньо під час осадження, $є$ методи 3 використанням оптичних (із застосуванням лазера) i ємнісних датчиків. Ці методи дозволяють визначати напруження в плівках під час їх початкового зростаня, тобто тоді, коли плівка складається з ізольованих острівців.

\section{2. Рентгеноструктурні вимірювання}

Рентгеноструктурний аналіз є потужним інструментом для виявлення характерних ознак мікроструктури плівок, зокрема для вимірювання параметрів кристалічної гратки. Деформація кристалічної гратки може бути визначена за результатами рентгенівської дифракції, а напруження розраховані 3 припущенням лінійного пружного викривлення гратки. Деталі теоретичних аспектів, а також інтерпретація вимірів за допомогою рентгеноструктурного аналізу докладно описано в роботі [70]. Найчастіше використовуються три техніки вимірювання напружень за допомогою рентгеноструктурного аналізу, які основані на моделі плоского напруженого стану; більш докладно з кожною можна ознайомитися в роботі [70].

Основним недоліком методик, основаних на рентгеноструктурному аналізі, $є$ відсутність можливості вимірювання напружень безпосередньо під час осадження.

\section{Висновки}

Незважаючи на велику кількість даних про існування напружень у тонких плівках і покриттях, на сьогоднішній день не існує загальної теорії, яка б описувала фрормування напружень в них. За результатами проведеного аналізу можна зробити висновок, що процеси формування напружень $є$ дуже чутливими до методу отримання плівок і покриттів, а також умов проведення експерименту. Існуючі моделі дозволяють лише частково зрозуміти природу розвитку напружень, а експериментальні результати часто суперечать один одному, що ставить під сумнів ту чи іншу модель. Крім того, жоден з механізмів не дозволяє ні кількісно ні якісно оцінити досягнення критичного стану в плівці, тобто визначити умови, що характеризують руйнування тонкоплівкових структур. Отже, розроблення моделі формування напружень в тонких плівках і покриттях з урахуванням фрізичних процесів, що впливають на остаточний розподіл, рівень напружень, і визначення їх критичних значень $€$ актуальним завданням. 


\section{Подяки}

Автор висловлює подяку Національному фонду досліджень України за підтримку (конкурс «Підтримка досліджень провідних та молодих учених», номер проєкту 2020.02/0119).

\section{Список літератури}

1. Mechanical behavior of metallic thin films on polymeric substrates and the effect of ion beam assistance on crack propagation / M. George, C. Coupeau,' J. Colin, J. Grilhé // Acta Materialia. - 2005. - Vol. 53. - iss. 2. - P. 411-417. DOI: https://doi.org/10.1016/j.actamat.2004.09.036

2. The influence of a brittle $\mathrm{Cr}$ interlayer on the deformation behavior of thin $\mathrm{Cu}$ films on flexible substrates: Experiment and model / V. M. Marxab, F. Tothc, A. Wiesinger, J. Berger, Ch. Kirchlechner, M. J. Cordill, F. D. Fischer, F. G. Rammerstorfer, G. Dehma // Acta Materialia. - 2015. - Vol. 89. - P. 278-289. DOI: https://doi.org/10.1016/j.actamat.2015.01.047

3. Atomic force microscopy study of the morphological shape of thin film buckling / C. Coupeau // Thin Solid Films. - 2002. - Vol. 406, - iss. 1-2. - P. 190194. DOl: https://doi.org/10.1016/S0040-6090(01)01772-2

4. An experimental study of the influence of imperfections on the buckling of compressed thin films / M.-W. Moon, J.-W. Chung, K.-R. Lee, K. H. Oh, R. Wang, A. G. Evans // Acta Materialia. - 2002. - Vol. 50. - iss. 5. - P. 1219-1227. DOl: https://doi.org/10.1016/S1359-6454(01)00423-2

5. How soft substrates affect the buckling delamination of thin films through crack front sink-in / R. Boijoux, G. Parry, J.-Y. Faou, C. Coupeau // Applied Physics Letters. - 2017. - Vol. 110. - iss. 14. - P. 141602. DOl: https://doi.org/10.1063/1.4979614

6. From telephone cords to branched buckles: A phase diagram / J.-Y. Faou, S. Grachev, E. Barthel, G. Parry // Acta Materialia. - 2017. - Vol. 125. - P. 524-531. DOI: https://doi.org/10.1016/j.actamat.2016.12.025

7. Enhanced Proton Conductivity in $\mathrm{Y}$-Doped $\mathrm{BaZrO}_{3}$ via Strain Engineering / A. Fluri, A. Marcolongo, V. Roddatis, A. Wokaun, D. Pergolesi, N. Marzari, T. Lippert // Advanced Science. - 2017. - Vol. 4. - iss. 12. - P. 1700467. DOI: https://doi.org/10.1002/advs.201700467

8. Growth stress induced tunability of dielectric permittivity in thin films / K. V. L. V. Narayanachari, H. Chandrasekar, A. Banerjee, K. B. R. Varma, R. Ranjan, N. Bhat, S. Raghavan // Journal of Applied Physics. - 2016. - Vol. 119. iss. 1. - P. 014106. DOI: https://doi.org/10.1063/1.4939466

9. Sander, D. The correlation between mechanical stress and magnetic anisotropy in ultrathin films / D. Sander // Reports on Progress in Physics. - 1999. Vol. 62. - iss. 5. - P. 809-858.

10. Sander, D. The role of surface stress in structural transitions, epitaxial growth and magnetism on the nanoscale / D. Sander, Z. Tian, J. Kirschner // Journal of Physics: Condensed Matter. - 2009. - Vol. 21, iss. 13. - P. 134015. DOI: https://doi.org/10.1088/0953-8984/21/13/134015

11. Lee, M. L. Strained Si, SiGe, and Ge channels for high-mobility metaloxide-semiconductor field-effect transistors / M. L. Lee, E. A. Fitzgerald // Journal of Applied Physics. - 2005. - Vol. 95. - iss. 1. - P. 011101. DOl: https://doi.org/10.1063/1.1819976 
12. Vertical Graphene Growth on SiO Microparticles for Stable Lithium Ion Battery Anodes / L. Shi, C. Pang, S. Chen, M. Wang, K. Wang, Z. Tan, P. Gao, J. Ren, Y. Huang, H. Peng, Z. Liu // Nano Letters. - 2017. - Vol. 17. - iss. 6. P. 3681-3687. DOI: https://doi.org/10.1021/acs.nanolett.7b00906

13. Growing vertical graphene sheets on natural graphite for fast charging lithium-ion batteries / Y. Mu, M. Han, J. Li, J. Liang, J. Yu // Carbon. - 2021. - Vol. 173. - P. 477-484. DOI: https://doi.org/10.1016/j.carbon.2020.11.027

14. Vertically-oriented graphene nanowalls: Growth and application in Li-ion batteries / Q. Yang, J. Wu, S. Li, L. Zhang, J. Fu, F. Huang, Q. Cheng // Diamond and Related Materials. - 2019. - Vol. 91. - P. 54-63. DOI: https://doi.org/10.1016/j.diamond.2018.11.007

15. Zhang, Z. Vertically Aligned Graphene Nanosheet Arrays: Synthesis, Properties and Applications in Electrochemical Energy Conversion and Storage / Z. Zhang, C.-S. Lee, W. Zhang // Advanced Energy Materials. - 2017. - Vol. 7. iss. 23. - P. 1700678. DOI: https://doi.org/10.1002/aenm.201700678

16. Facile growth of vertically-aligned graphene nanosheets via thermal CVD: The experimental and theoretical investigations / H. Wang, E. Gao, P.Liu, D. Zhou, D. Geng, X. Xue, L. Wang, K. Jiang, Z. Xu, G. Yu // Carbon. - 2017. - Vol. 121. P. 1-9. DOI: https://doi.org/10.1016/j.carbon.2017.05.074

17. Study of CuO Nanowire Growth on Different Copper Surfaces / G. FritzPopovski, F. Sosada-Ludwikowska, A. Köck, J. Keckes, G. A. Maier // Scientific Reports. - 2019. - Vol. 9. - P. 1-13. DOI: https://doi.org/10.1038/s41598-01837172-8

18. $\mathrm{Cu}_{2} \mathrm{O} / \mathrm{CuO}$ heterojunction catalysts through atmospheric pressure plasma induced defect passivation / Avishek Dey, Gauthaman Chandrabose, A. Lois, O. Damptey, E. S. Erakulan, R. Thapa, S. Zhuk, G. K. Dalapati, S. Ramakrishna, N. St. J. Braithwaite, A. Shirzadi, S. Krishnamurthy / Applied Surface Science. 2021. - Vol. 541. - P. 148571. DOI: https://doi.org/10.1016/j.apsusc.2020.148571

19. Macroscale synthesis of $\mathrm{CuO}$ nanowires on FTO plane substrate / Y. Mabuchi, R. N. Mohamed, X. Li, J. Liang, N. Kishi, T. Soga // Modern Physics Letters B. - 2019. - Vol. 33. - iss. 11. - P. 1950138. DOl: https://doi.org/10.1142/S0217984919501380

20. Adsorption of $\mathrm{H} 2, \mathrm{CO} 2, \mathrm{CH} 4, \mathrm{CO}, \mathrm{N} 2$ and $\mathrm{H} 2 \mathrm{O}$ in activated Carbon and Zeolite for Hydrogen production / F. V. S. Lopes, C. A. Grande, A. M. Ribeiro, J. M. Loureiro, O. Evaggelos, V. Nikolakis, A. E. Rodrigues // Separation Science and Technology. - 2009. - Vol. 44. - P. 1045-1073. DOI: https://doi.org/10.1080/01496390902729130

21. Adsorption of $\mathrm{CO} 2, \mathrm{CH} 4$, and $\mathrm{N} 2$ in Activated Carbon Honeycomb Monolith / R. P. Ribeiro, T. P. Sauer, F. V. Lopes, R. F. Moreira, C. A. Grande, A. E. Rodrigues // Journal of Chemical \& Engineering Data. - 2008. - Vol. 53. - P. 2311-2317. DOI: https://doi.org/10.1021/je800161m

22. Baranov, O. Towards a highly-controllable synthesis of copper oxide nanowires in radio-frequency reactive plasma: fast saturation at the targeted size / O. Baranov, G. Filipič, U. Cvelbar // Plasma Sources Science and Technology. 2019. - № 28. - P. 084002. DOI: https://doi.org/10.1088/1361-6595/aae12e

23. Баранов, О. О. Теоретична модель формування одновимірних наноструктур оксиду міді в умовах плазмового середовища [Текст] / О. О. Баранов // Відкриті інформаційні та комп'ютерні інтегровані технології : 
Нац. аерокосм. ун-т ім. М. Є. Жуковського «Харк. авіац. ін-т». - Харків, 2020. № 88. - C. 141 - 161. DOI: https://doi.org/10.32620/oikit.2020.88.11

24. Teixeira, V. Residual stress and cracking in thin PVD coatings / V. Teixeira // Vacuum. - 2002. - Vol. 64. - iss. 3-4. - P. 393-399. DOI: https://doi.org/10.1016/S0042-207X(01)00327-X

25. Thornton, J.A. Stress-related effects in thin films / J.A. Thornton, D. Hoffman // Thin Solid Films. - 1989. - Vol. 171. - iss. 1. - P. 5-31. DOI: https://doi.org/10.1016/0040-6090(89)90030-8

26. Hunt, R. A model of deadherence due to stresses in an elastic film / R. Hunt, B. Gale // Journal of Physics D: Applied Physics. - 1972. - Vol. 5. - iss. 2. P. 359-372. DOI: https://doi.org/10.1088/0022-3727/5/2/318

27. Finegan, J., Hoffman, R. AEC Technical Report No. 18 / J. Finegan, R. Hoffman. - Case Institute of Technology, Cleveland, $1961-34$ p.

28. Rottmayer, R. E. Solid state physics program. Growth effects thin nickel films: Technical Report No. 79 / R. E. Rottmayer. - Case Western Reserve Univ., Cleveland, Ohio., 1972. -78 p.

29. Koch, R. Microstructural changes in vapour-deposited silver, copper and gold films investigated by internal stress measurements / R. Koch, R. Abermann // Thin Solid Films. - 1986. - Vol. 140. - iss. 2. - P. 217-226. DOI: https://doi.org/10.1016/0040-6090(86)90265-8

30. Chaudhari, P. Grain growth and stress relief in thin films / P Chaudhari // Journal of Vacuum Science and Technology. - 1972. - Vol. 9. - iss. 1. - P. 520-522. DOI: https://doi.org/10.1116/1.1316674

31. Doerner, M. F., Nix, W.D. Stresses and deformation processes in thin films on substrates / M. F. Doerner, W. D. Nix // Critical Reviews in Solid State and Material Sciences. - 1988. - Vol. 14. - iss. 3. - P. 225-268. DOI: https://doi.org/10.1080/10408438808243734

32. D'Heurle, F. M. Aluminum films deposited by rf sputtering / F. M. D'Heurle // Metall. Trans. - 1970. - Vol. 1. - iss. 3. - P. 725-732. DOI: https://doi.org/10.1007/BF02811600

33. Windischmann, $H$. An intrinsic stress scaling law for polycrystalline thin films prepared by ion beam sputtering / H. Windischmann // J. Appl. Phys. - 1987. Vol. 62. - iss. 5. - P. 1800-1807. DOI: https://doi.org/10.1063/1.339560

34. Abermann, R., Koch, R. In situ study of thin film growth by internal stress measurement under ultrahigh vacuum conditions: Silver and copper under the influence of oxygen / R. Abermann, R. Koch // Thin Solid Films. - 1986. - Vol. 142. iss 1. - P. 65-76.

35. Sigmund, P. Sputtering by ion bombardment theoretical concepts. In: Behrisch R. (eds) Sputtering by Particle Bombardment I. Topics in Applied Physics. Springer, Berlin, Heidelberg. - 1981. - Vol. 47.- P. 9-71. DOI: https://doi.org/10.1007/3540105212_7

36. Effect of ion bombardment during deposition on the x-ray microstructure of thin silver films / T. C. Huang, G. Lim, F. Parmigiani, E. Kay // Journal of Vacuum Science \& Technology A. - 1985. - Vol. 3. - iss. 6. - P. 2161-2166. DOI: https://doi.org/10.1116/1.573271

37. Kay, E. Effect of energetic neutralized noble gas ions on the structure of ion beam sputtered thin metal films / E. Kay, F. Parmigiani, W. Parrish // Journal of Vacuum Science \& Technology A. - 1987. - Vol. 5. - iss. 1. - P. 44-51. DOI: https://doi.org/10.1116/1.574135 
38. Windischmann, H. Intrinsic stress in sputter-deposited thin films // Crit. Rev. Solid State Mater. Sci. - 1992. - Vol. 17. - iss. 6. - P. 547-596. DOI: https://doi.org/10.1080/10408439208244586

39. On the origin of stress in magnetron sputtered TiN layers / J.-D. Kamminga, Th. H. de Keijser, R. Delhez, E. J Mittemeijer // J. Appl. Phys. 2000. - Vol. 88. - iss. 11. - P. 6332-6345. DOI: https://doi.org/10.1063/1.1319973

40. Abadias, G. Diffraction stress analysis in fiber-textured TiN films grown by io-beam sputtering: Application to (001) and mixed (001)+(111) texture / G. Abadias, Y. Y. Tse // J. App. Phys. - 2004. - Vol. 95. - iss. 5. - P. 2414-2428. DOI: https://doi.org/10.1063/1.1646444

41. Stress field in sputtered thin films: Ion irradiation as a tool to induce relaxation and investigate the origin of growth stress / A. Debelle, G. Abadias, A. Michel, C. Jaouen // J. Appl. Phys. - 2004. - Vol. 84. - iss. 24. - P. 5034-5036. DOI: https://doi.org/10.1063/1.1763637

42. Doerner, M. F. Stresses and deformation processes in thin films on substrates / M. F. Doerner, W. D. Nix // Crit. Rev. Solid State Mater. Sci. - 1988. Vol. 14. - iss. 3. - P. 225- 268. DOI: https://doi.org/10.1080/10408438808243734

43. White, G. E. In situ study of film stresses in metal silicides using absorption-edge-contour mapping / G. E. White, H. Chen // J. Appl. Phys. - 1990. Vol. 68. -iss. 7. - P. 3317-3321. DOI: https://doi.org/10.1063/1.346384

44. Buaud, P. P. In situ strain measurements during the formation of platinum silicide films / P. P. Buaud, F. M. d'Heurle, E. A. Irene, B. K. Patnaik, N. R. Parikh // J. Vac. Sci. Technol. B. - 1991. - Vol. 9. - iss. 5. - P. 2536-2541. DOl: https://doi.org/10.1116/1.585688

45. Gergaud, P. Chenevier Stresses arising from a solid state reactions between palladium films and $\mathrm{Si}(001)$ investigated by in situ combined x-ray diffraction and curvature measurements / P. Gergaud, O. Thomas // J. Appl. Phys. - 2003. Vol. 94. - iss. 3. - P. 1584-1591. DOI: https://doi.org/10.1063/1.1590059

46. Abermann, R. Internal stress of vapour-deposited aluminium films: Effect of $\mathrm{O}_{2}$ and water vapour present during film deposition / R. Abermann // Thin Solid Films. - 1990. - Vol. 186. - iss. 2. - P. 233-240. DOI: https://doi.org/10.1016/00406090(90)90145-4

47. Murakami, M. Deformation in thin films by thermal strain / M. Murakami // J. Vac. Sci. Techchnol. - 1991. - Vol. 9. - iss. 4. - P. 2469-2476. DOI: https://doi.org/10.1116/1.577258

48. Time dependence of stress and hillock distributions during electromigration in thin metal film interconnections / L. Klinger, E. Glickman, A. Katsman, L. Levin // Mater. Sci. Eng. B. - 1994. - Vol. 23. - iss. 1. - P. 15-18. DOl: https://doi.org/10.1016/0921-5107(94)90271-2

49. The influence of sputter-deposition parameters on piezoelectric and mechanical properties of AIN thin films / A. Ababneh, U. Schmid, J. Hernando, J. L. Sanchez-Rajas, H. Seidel // Mater. Sci. Eng. B. - 2010. - Vol. 172. - iss. 3. P. 253-258. DOI: https://doi.org/10.1016/j.mseb.2010.05.026

50. Dutta, S. Ferroelectric and piezoelectric properties of (111) oriented lanthanum modified lead zirconate titanate film / S. Dutta, A. A. Jeyaseelan, S. Sruthi // Thin Solid Films. - 2014. - Vol. 562. - P. 190-194. DOI: https://doi.org/10.1016/j.tsf.2014.04.072 
51. Enhancement of piezoelectric response of diluted Ta doped AIN / H. Liu, F. Zeng, G. Tang, F. Pan // Appl. Surf. Sci. - 2013. - Vol. 270. - P. 225-230. DOI: https://doi.org/10.1016/j.apsusc.2013.01.005

52. Electrostriction: nonlinear electromechanical coupling in solid dielectrics / R. E. Newnham, V. Sundar, R. Yimnirun, J. Su, Q. M. Zhang // J. Phys. Chem. B. 1997. - Vol. 101. - iss. 48. - P. 10141-10150. DOI: https://doi.org/10.1021/jp971522c

53. Direct and inverse measurement of thin film magnetostriction / J.-Ph. Jay, F. Le Berre, S. P. Pogossian, M. V. Indenbom // J. Magn. Mag. Mater. - 2010. Vol. 322. - iss. 15. - P. 2203-2214. DOI: https://doi.org/10.1016/j.jmmm.2010.02.011

54. Magnetostriction measurement in thin films using laser Doppler vibrometry / R. Varghese, R. Viswan, K. Joshi, S. Seifikar, Y. Zhou, J. Schwartz, S. Priya // J. Magn. Mag. Mater. - 2014. - Vol. 383. - 179-187. DOI: https://doi.org/10.1016/j.jmmm.2014.03.076

55. Shintani, A. Temperature dependence of stresses in chemical vapor deposited vitreous films / A. Shintani, S. Sugaki, H. Nakashima // J. Appl. Phys. 1980. - Vol. 51. - iss. 8. - P. 4197-4205. DOI: https://doi.org/10.1063/1.328277

56. Lee, C.-C. Modeling and validation of mechanical stress in indium tin oxide layer integrated in highly flexible stacked thin films / C.-C. Lee // Thin Solid Films. 2013. - Vol. 544. - P. 443-447. DOI: https://doi.org/10.1016/j.tsf.2013.02.084

57. Mastering the biaxial stress state in nanometric thin films on flexible substrates / D. Faurie, P.-O. Renault, E. Le Bourhis, G. Geandier, P. Goudeau, D. Thiaudiere // Appl. Surf. Sci. - 2014. - Vol. 306. - P. 70-74. DOI: https://doi.org/10.1016/j.apsusc.2014.02.032

58. Stoney, G. G. The Tension of Metallic Films Deposited by Electrolysis // Proceedings of the Royal Society of London. Series A. - 1909. - Vol. 82. - iss. 553. - P. $172-175$.

59. Janssen, G. Celebrating the 100th anniversary of the Stoney equation for film stress: Developments from polycrystalline steel strips to single crystal silicon wafers / G. Janssen,, M. M. Abdalla, F.van Keulen, B. R. Pujada, B.van Venrooy // Thin Solid Films. - 2009. - Vol. 517. - iss. 6. - P. 1858-1867. DOI: https://doi.org/10.1016/j.tsf.2008.07.014

60. Shull, A. L. Measurements of stress during vapor deposition of copper and silver thin films and multilayers / A. L. Shull, F. Spaepen // Journal of Applied Physics. - 1996. - Vol. 80. - iss. 11. - P. 6243-6256. DOI: https://doi.org/10.1063/1.363701

61. Pan, J. Insitu stress measurement of refractory metal silicides during sintering / J. Pan, I. Blech // Journal of Applied Physics. - 1984. - Vol. 55. - iss. 8. P. 2874-2880. DOI: https://doi.org/10.1063/1.333326

62. Martinez, R. E. Direct measurement of crystal surface stress / R. E. Martinez, W. M. Augustyniak, J. A. Golovchenko // Physical Review Letters. 1990. - Vol. 64. - iss. 9. - P. 1035- 1038. DOI: https://doi.org/10.1103/PhysRevLett.64.1035

63. Moske, M. New UHV dilatometer for precise measurement of internal stresses in thin binary-alloy films from 20 to $750 \mathrm{~K} / \mathrm{M}$. Moske, K. Samwer // Review of Scientific Instruments. - 1988. - Vol. 59. - iss. 9. - P. 2012-2017. DOI: https://doi.org/10.1063/1.1140017 
64. Wilcock, J. A sensitive bending beam apparatus for measuring the stress in evaporated thin films / J. Wilcock, D. Campbell // Thin Solid Films. - 1969. - Vol. 3. - iss. 1. - P. 3-12. DOI: https://doi.org/10.1016/0040-6090(69)90107-2

65. Yu, Y.-T. Evaluation of residual stresses in thin films by critical buckling observation of circular microstructures and finite element method / Y.-T. Yu, W.-Z. Yuan, D.-Y. Qiao, Q. Liang // Thin Solid Films. - 2008. - Vol. 516. - iss. 12. P. 4070-4075. DOI: https://doi.org/10.1016/j.tsf.2007.12.153

66. Blackburn, $\mathrm{H}$. The development of stress and surface temperature during deposition of lithium fluoride films / H. Blackburn, D.Campbell // Philosophical Magazine. - 1963. - Vol. 8. - iss. 89. - P. 823-831. DOI: https://doi.org/10.1080/14786436308213839

67. Story, H. Stress Annealing in Vacuum Deposited Copper Films / H. Story, R. Hoffman // Proceedings of the Physical Society. Section B. - 1957. - Vol. 70. iss. 10. - P. 950.

68. Priest, J. Stress anisotropy in silicon oxide films / J. Priest, H. Caswell, Y. Budo // Journal of Applied Physics. - 1963. - Vol. 34. - iss. 2. - P. 347-351. DOI: https://doi.org/10.1063/1.1702611

69. Priest, J. R. Apparatus for the Measurement of Stress in Vacuum Evaporated Films / J. R. Priest // Review of Scientific Instruments. - 1961. - Vol. 32. - iss. 12. - P. 1349-1351. DOI: https://doi.org/10.1063/1.1717249

70. Prevey, P. S. X-ray diffraction residual stress techniques / P. S. Prevéy, D. J. Hornbach. - ASM International, ASM Handbook. - 1986. - Vol. 10. - P. 380392. DOI: https://doi.org/10.31399/asm.hb.v10.a0006632

\section{References}

1. Mechanical behavior of metallic thin films on polymeric substrates and the effect of ion beam assistance on crack propagation / M. George, C. Coupeau,' J. Colin, J. Grilhé // Acta Materialia. - 2005. - Vol. 53. - iss. 2. - P. 411-417. DOI: https://doi.org/10.1016/j.actamat.2004.09.036

2. The influence of a brittle $\mathrm{Cr}$ interlayer on the deformation behavior of thin $\mathrm{Cu}$ films on flexible substrates: Experiment and model / V. M. Marxab, F. Tothc, A. Wiesinger, J. Berger, Ch. Kirchlechner, M. J. Cordill, F. D. Fischer, F. G. Rammerstorfer, G. Dehma // Acta Materialia. - 2015. - Vol. 89. - P. 278-289. DOI: https://doi.org/10.1016/j.actamat.2015.01.047

3. Atomic force microscopy study of the morphological shape of thin film buckling / C. Coupeau // Thin Solid Films. - 2002. - Vol. 406, - iss. 1-2. - P. 190194. DOI: https://doi.org/10.1016/S0040-6090(01)01772-2

4. An experimental study of the influence of imperfections on the buckling of compressed thin films / M.-W. Moon, J.-W. Chung, K.-R. Lee, K. H. Oh, R. Wang, A. G. Evans // Acta Materialia. - 2002. - Vol. 50. - iss. 5. - P. 1219-1227. DOl: https://doi.org/10.1016/S1359-6454(01)00423-2

5. How soft substrates affect the buckling delamination of thin films through crack front sink-in / R. Boijoux, G. Parry, J.-Y. Faou, C. Coupeau // Applied Physics Letters. - 2017. - Vol. 110. - iss. 14. - P. 141602. DOl: https://doi.org/10.1063/1.4979614

6. From telephone cords to branched buckles: A phase diagram / J.-Y. Faou, S. Grachev, E. Barthel, G. Parry // Acta Materialia. - 2017. - Vol. 125. - P. 524-531. DOI: https://doi.org/10.1016/j.actamat.2016.12.025 
7. Enhanced Proton Conductivity in $\mathrm{Y}$-Doped $\mathrm{BaZrO}_{3}$ via Strain Engineering / A. Fluri, A. Marcolongo, V. Roddatis, A. Wokaun, D. Pergolesi, N. Marzari, T. Lippert // Advanced Science. - 2017. - Vol. 4. - iss. 12. - P. 1700467. DOI: https://doi.org/10.1002/advs.201700467

8. Growth stress induced tunability of dielectric permittivity in thin films / K. V. L. V. Narayanachari, H. Chandrasekar, A. Banerjee, K. B. R. Varma, R. Ranjan, N. Bhat, S. Raghavan // Journal of Applied Physics. - 2016. - Vol. 119. iss. 1. - P. 014106. DOI: https://doi.org/10.1063/1.4939466

9. Sander, D. The correlation between mechanical stress and magnetic anisotropy in ultrathin films / D. Sander // Reports on Progress in Physics. - 1999. Vol. 62. - iss. 5. - P. 809-858.

10. Sander, D. The role of surface stress in structural transitions, epitaxial growth and magnetism on the nanoscale / D. Sander, Z. Tian, J. Kirschner // Journal of Physics: Condensed Matter. - 2009. - Vol. 21, iss. 13. - P. 134015. DOI: https://doi.org/10.1088/0953-8984/21/13/134015

11. Lee, M. L. Strained Si, SiGe, and Ge channels for high-mobility metaloxide-semiconductor field-effect transistors / M. L. Lee, E. A. Fitzgerald // Journal of Applied Physics. - 2005. - Vol. 95. - iss. 1. - P. 011101. DOl: https://doi.org/10.1063/1.1819976

12. Vertical Graphene Growth on SiO Microparticles for Stable Lithium Ion Battery Anodes / L. Shi, C. Pang, S. Chen, M. Wang, K. Wang, Z. Tan, P. Gao, J. Ren, Y. Huang, H. Peng, Z. Liu // Nano Letters. - 2017. - Vol. 17. - iss. 6. P. 3681-3687. DOI: https://doi.org/10.1021/acs.nanolett.7b00906

13. Growing vertical graphene sheets on natural graphite for fast charging lithium-ion batteries / Y. Mu, M. Han, J. Li, J. Liang, J. Yu // Carbon. - 2021. Vol. 173. - P. 477-484. DOI: https://doi.org/10.1016/j.carbon.2020.11.027

14. Vertically-oriented graphene nanowalls: Growth and application in Li-ion batteries / Q. Yang, J. Wu, S. Li, L. Zhang, J. Fu, F. Huang, Q. Cheng // Diamond and Related Materials. - 2019. - Vol. 91. - P. 54-63. DOI: https://doi.org/10.1016/j.diamond.2018.11.007

15. Zhang, Z. Vertically Aligned Graphene Nanosheet Arrays: Synthesis, Properties and Applications in Electrochemical Energy Conversion and Storage / Z. Zhang, C.-S. Lee, W. Zhang // Advanced Energy Materials. - 2017. - Vol. 7. - iss. 23. - P. 1700678. DOI: https://doi.org/10.1002/aenm.201700678

16. Facile growth of vertically-aligned graphene nanosheets via thermal CVD: The experimental and theoretical investigations / H. Wang, E. Gao, P.Liu, D. Zhou, D. Geng, X. Xue, L. Wang, K. Jiang, Z. Xu, G. Yu // Carbon. - 2017. - Vol. 121. P. 1-9. DOI: https://doi.org/10.1016/j.carbon.2017.05.074

17. Study of CuO Nanowire Growth on Different Copper Surfaces / G. Fritz-Popovski, F. Sosada-Ludwikowska, A. Köck, J. Keckes, G. A. Maier // Scientific Reports. - 2019. - Vol. 9. - P. 1-13. DOI: https://doi.org/10.1038/s41598018-37172-8

18. $\mathrm{Cu}_{2} \mathrm{O} / \mathrm{CuO}$ heterojunction catalysts through atmospheric pressure plasma induced defect passivation / Avishek Dey, Gauthaman Chandrabose, A. Lois, O. Damptey, E.S. Erakulan, R. Thapa, S. Zhuk, G. K. Dalapati, S. Ramakrishna, N. St. J. Braithwaite, A. Shirzadi, S. Krishnamurthy / Applied Surface Science. 2021. - Vol. 541. - P. 148571. DOI: https://doi.org/10.1016/j.apsusc.2020.148571

19. Macroscale synthesis of $\mathrm{CuO}$ nanowires on FTO plane substrate / Y. Mabuchi, R. N. Mohamed, X. Li, J. Liang, N. Kishi, T. Soga // Modern Physics 
Відкриті інформаційні та комп'ютерні інтегровані технології, № 91, 2021

Letters B. - 2019. - Vol. 33. - iss. 11. - P. 1950138. DOI: https://doi.org/10.1142/S0217984919501380

20. Adsorption of $\mathrm{H} 2, \mathrm{CO} 2, \mathrm{CH} 4, \mathrm{CO}, \mathrm{N} 2$ and $\mathrm{H} 2 \mathrm{O}$ in activated Carbon and Zeolite for Hydrogen production / F. V. S. Lopes, C. A. Grande, A. M. Ribeiro, J. M. Loureiro, O. Evaggelos, V. Nikolakis, A. E. Rodrigues // Separation Science and Technology. - 2009. - Vol. 44. - P. 1045-1073. DOI: https://doi.org/10.1080/01496390902729130

21. Adsorption of $\mathrm{CO} 2, \mathrm{CH} 4$, and $\mathrm{N} 2$ in Activated Carbon Honeycomb Monolith / R. P. Ribeiro, T. P. Sauer, F. V. Lopes, R. F. Moreira, C. A. Grande, A. E. Rodrigues // Journal of Chemical \& Engineering Data. - 2008. - Vol. 53. P. 2311-2317. DOI: https://doi.org/10.1021/je800161m

22. Baranov, O. Towards a highly-controllable synthesis of copper oxide nanowires in radio-frequency reactive plasma: fast saturation at the targeted size / O. Baranov, G. Filipič, U. Cvelbar // Plasma Sources Science and Technology. 2019. - № 28. - P. 084002. DOI: https://doi.org/10.1088/1361-6595/aae12e

23. Baranov, O. O. Teoretična model' formuvannâ odnovimìrnih nanostruktur oksidu mìdì v umovah plazmovogo seredoviŝa / O. O. Baranov // Vìdkritì ìnformacìjnì ta komp'ûternì ìntegrovanì tehnologiï : Nacìonal'nij aerokosmičnij unìversitet ìm. M. É. Žukovs'kogo "Harkìvs'kij avìacìnij ìnstitut». - Harkìv, 2020. - № 88. S. 141 - 161. DOI: https://doi.org/10.32620/oikit.2020.88.11

24. Teixeira, V. Residual stress and cracking in thin PVD coatings / V. Teixeira // Vacuum. - 2002. - Vol. 64. - iss. 3-4. - P. 393-399. DOI: https://doi.org/10.1016/S0042-207X(01)00327-X

25. Thornton, J.A. Stress-related effects in thin films / J.A. Thornton, D. Hoffman // Thin Solid Films. - 1989. - Vol. 171. - iss. 1. - P. 5-31. DOI: https://doi.org/10.1016/0040-6090(89)90030-8

26. Hunt, R. A model of deadherence due to stresses in an elastic film / R. Hunt, B. Gale // Journal of Physics D: Applied Physics. - 1972. - Vol. 5. - iss. 2. P. 359-372. DOI: https://doi.org/10.1088/0022-3727/5/2/318

27. Finegan, J., Hoffman, R. AEC Technical Report No. 18 / J. Finegan, R. Hoffman. - Case Institute of Technology, Cleveland, $1961-34$ p.

28. Rottmayer, R. E. Solid state physics program. Growth effects thin nickel films: Technical Report No. 79 / R. E. Rottmayer. - Case Western Reserve Univ., Cleveland, Ohio., 1972. - 78 p.

29. Koch, R. Microstructural changes in vapour-deposited silver, copper and gold films investigated by internal stress measurements / R. Koch, R. Abermann // Thin Solid Films. - 1986. - Vol. 140. - iss. 2. - P. 217-226. DOI: https://doi.org/10.1016/0040-6090(86)90265-8

30. Chaudhari, P. Grain growth and stress relief in thin films / P Chaudhari // Journal of Vacuum Science and Technology. - 1972. - Vol. 9. - iss. 1. - P. 520-522. DOI: https://doi.org/10.1116/1.1316674

31. Doerner, M. F., Nix, W.D. Stresses and deformation processes in thin films on substrates / M. F. Doerner, W. D. Nix // Critical Reviews in Solid State and Material Sciences. - 1988. - Vol. 14. - iss. 3. - P. 225-268. DOl: https://doi.org/10.1080/10408438808243734

32. D'Heurle, F. M. Aluminum films deposited by rf sputtering / F. M. D'Heurle // Metall. Trans. - 1970. - Vol. 1. - iss. 3. - P. 725-732. DOI: https://doi.org/10.1007/BF02811600 
33. Windischmann, H. An intrinsic stress scaling law for polycrystalline thin films prepared by ion beam sputtering / H. Windischmann // J. Appl. Phys. - 1987. Vol. 62. - iss. 5. - P. 1800-1807. DOI: https://doi.org/10.1063/1.339560

34. Abermann, R., Koch, R. In situ study of thin film growth by internal stress measurement under ultrahigh vacuum conditions: Silver and copper under the influence of oxygen / R. Abermann, R. Koch // Thin Solid Films. - 1986. - Vol. 142. iss 1. - P. 65-76.

35. Sigmund, P. Sputtering by ion bombardment theoretical concepts. In: Behrisch R. (eds) Sputtering by Particle Bombardment I. Topics in Applied Physics. Springer, Berlin, Heidelberg. - 1981. - Vol. 47.- P. 9-71. DOI: https://doi.org/10.1007/3540105212_7

36. Effect of ion bombardment during deposition on the x-ray microstructure of thin silver films / T. C. Huang, G. Lim, F. Parmigiani, E. Kay // Journal of Vacuum Science \& Technology A. - 1985. - Vol. 3. - iss. 6. - P. 2161-2166. DOI: https://doi.org/10.1116/1.573271

37. Kay, E. Effect of energetic neutralized noble gas ions on the structure of ion beam sputtered thin metal films / E. Kay, F. Parmigiani, W. Parrish // Journal of Vacuum Science \& Technology A. - 1987. - Vol. 5. - iss. 1. - P. 44-51. DOI: https://doi.org/10.1116/1.574135

38. Windischmann, $\mathrm{H}$. Intrinsic stress in sputter-deposited thin films // Crit. Rev. Solid State Mater. Sci. - 1992. - Vol. 17. - iss. 6. - P. 547-596. DOI: https://doi.org/10.1080/10408439208244586

39. On the origin of stress in magnetron sputtered TiN layers / J.-D. Kamminga, Th. H. de Keijser, R. Delhez, E. J Mittemeijer // J. Appl. Phys. 2000. - Vol. 88. - iss. 11. - P. 6332-6345. DOI: https://doi.org/10.1063/1.1319973

40. Abadias, G. Diffraction stress analysis in fiber-textured TiN films grown by io-beam sputtering: Application to (001) and mixed (001)+(111) texture / G. Abadias, Y. Y. Tse // J. App. Phys. - 2004. - Vol. 95. - iss. 5. - P. 2414-2428. DOI: https://doi.org/10.1063/1.1646444

41. Stress field in sputtered thin films: Ion irradiation as a tool to induce relaxation and investigate the origin of growth stress / A. Debelle, G. Abadias, A. Michel, C. Jaouen // J. Appl. Phys. - 2004. - Vol. 84. - iss. 24. - P. 5034-5036. DOI: https://doi.org/10.1063/1.1763637

42. Doerner, M. F. Stresses and deformation processes in thin films on substrates / M. F. Doerner, W. D. Nix // Crit. Rev. Solid State Mater. Sci. - 1988. Vol. 14. - iss. 3. - P. 225- 268. DOI: https://doi.org/10.1080/10408438808243734

43. White, G. E. In situ study of film stresses in metal silicides using absorption-edge-contour mapping / G. E. White, H. Chen // J. Appl. Phys. - 1990. Vol. 68. -iss. 7. - P. 3317-3321. DOI: https://doi.org/10.1063/1.346384

44. Buaud, P. P. In situ strain measurements during the formation of platinum silicide films / P. P. Buaud, F. M. d'Heurle, E. A. Irene, B. K. Patnaik, N. R. Parikh // J. Vac. Sci. Technol. B. - 1991. - Vol. 9. - iss. 5. - P. 2536-2541. DOI: https://doi.org/10.1116/1.585688

45. Gergaud, P. Chenevier Stresses arising from a solid state reactions between palladium films and $\mathrm{Si}(001)$ investigated by in situ combined x-ray diffraction and curvature measurements / P. Gergaud, O. Thomas // J. Appl. Phys. - 2003. Vol. 94. - iss. 3. - P. 1584-1591. DOl: https://doi.org/10.1063/1.1590059

46. Abermann, R. Internal stress of vapour-deposited aluminium films: Effect of $\mathrm{O}_{2}$ and water vapour present during film deposition / R. Abermann // Thin Solid 
Films. - 1990. - Vol. 186. - iss. 2. - P. 233-240. DOI: https://doi.org/10.1016/00406090(90)90145-4

47. Murakami, M. Deformation in thin films by thermal strain / M. Murakami // J. Vac. Sci. Techchnol. - 1991. - Vol. 9. - iss. 4. - P. 2469-2476. DOI: https://doi.org/10.1116/1.577258

48. Time dependence of stress and hillock distributions during electromigration in thin metal film interconnections / L. Klinger, E. Glickman, A. Katsman, L. Levin // Mater. Sci. Eng. B. - 1994. - Vol. 23. - iss. 1. - P. 15-18. DOl: https://doi.org/10.1016/0921-5107(94)90271-2

49. The influence of sputter-deposition parameters on piezoelectric and mechanical properties of AIN thin films / A. Ababneh, U. Schmid, J. Hernando, J. L. Sanchez-Rajas, H. Seidel // Mater. Sci. Eng. B. - 2010. - Vol. 172. - iss. 3. P. 253-258. DOI: https://doi.org/10.1016/j.mseb.2010.05.026

50. Dutta, S. Ferroelectric and piezoelectric properties of (111) oriented lanthanum modified lead zirconate titanate film / S. Dutta, A. A. Jeyaseelan, S. Sruthi // Thin Solid Films. - 2014. - Vol. 562. - P. 190-194. DOI: https://doi.org/10.1016/j.tsf.2014.04.072

51. Enhancement of piezoelectric response of diluted Ta doped AIN / H. Liu, F. Zeng, G. Tang, F. Pan // Appl. Surf. Sci. - 2013. - Vol. 270. - P. 225-230. DOI: https://doi.org/10.1016/j.apsusc.2013.01.005

52. Electrostriction: nonlinear electromechanical coupling in solid dielectrics / R. E. Newnham, V. Sundar, R. Yimnirun, J. Su, Q. M. Zhang // J. Phys. Chem. B. 1997. - Vol. 101. - iss. 48. - P. 10141-10150. DOI: https://doi.org/10.1021/jp971522c

53. Direct and inverse measurement of thin film magnetostriction / J.-Ph. Jay, F. Le Berre, S. P. Pogossian, M. V. Indenbom // J. Magn. Mag. Mater. - 2010. Vol. 322. - iss. 15. - P. 2203-2214. DOI: https://doi.org/10.1016/j.jmmm.2010.02.011

54. Magnetostriction measurement in thin films using laser Doppler vibrometry / R. Varghese, R. Viswan, K. Joshi, S. Seifikar, Y. Zhou, J. Schwartz, S. Priya // J. Magn. Mag. Mater. - 2014. - Vol. 383. - 179-187. DOI: https://doi.org/10.1016/j.jmmm.2014.03.076

55. Shintani, A. Temperature dependence of stresses in chemical vapor deposited vitreous films / A. Shintani, S. Sugaki, H. Nakashima // J. Appl. Phys. 1980. - Vol. 51. - iss. 8. - P. 4197-4205. DOl: https://doi.org/10.1063/1.328277

56. Lee, C.-C. Modeling and validation of mechanical stress in indium tin oxide layer integrated in highly flexible stacked thin films / C.-C. Lee // Thin Solid Films. 2013. - Vol. 544. - P. 443-447. DOI: https://doi.org/10.1016/j.tsf.2013.02.084

57. Mastering the biaxial stress state in nanometric thin films on flexible substrates / D. Faurie, P.-O. Renault, E. Le Bourhis, G. Geandier, P. Goudeau, D. Thiaudiere // Appl. Surf. Sci. - 2014. - Vol. 306. - P. 70-74. DOI: https://doi.org/10.1016/j.apsusc.2014.02.032

58. Stoney, G. G. The Tension of Metallic Films Deposited by Electrolysis // Proceedings of the Royal Society of London. Series A. - 1909. - Vol. 82. - iss. 553. - P. 172-175.

59. Janssen, G. Celebrating the 100th anniversary of the Stoney equation for film stress: Developments from polycrystalline steel strips to single crystal silicon wafers / G. Janssen,, M. M. Abdalla, F.van Keulen, B. R. Pujada, B.van Venrooy // Thin Solid Films. - 2009. - Vol. 517. - iss. 6. - P. 1858-1867. DOI: https://doi.org/10.1016/j.tsf.2008.07.014 
60. Shull, A. L. Measurements of stress during vapor deposition of copper and silver thin films and multilayers / A. L. Shull, F. Spaepen // Journal of Applied Physics. - 1996. - Vol. 80. - iss. 11. - P. 6243-6256. DOl: https://doi.org/10.1063/1.363701

61. Pan, J. Insitu stress measurement of refractory metal silicides during sintering / J. Pan, I. Blech // Journal of Applied Physics. - 1984. - Vol. 55. - iss. 8. P. 2874-2880. DOI: https://doi.org/10.1063/1.333326

62. Martinez, R. E. Direct measurement of crystal surface stress / R. E. Martinez, W. M. Augustyniak, J. A. Golovchenko // Physical Review Letters. 1990. - Vol. 64. - iss. 9. - P. 1035- 1038. DOI: https://doi.org/10.1103/PhysRevLett.64.1035

63. Moske, M. New UHV dilatometer for precise measurement of internal stresses in thin binary-alloy films from 20 to $750 \mathrm{~K} / \mathrm{M}$. Moske, K. Samwer // Review of Scientific Instruments. - 1988. - Vol. 59. - iss. 9. - P. 2012-2017. DOI: https://doi.org/10.1063/1.1140017

64. Wilcock, J. A sensitive bending beam apparatus for measuring the stress in evaporated thin films / J. Wilcock, D. Campbell // Thin Solid Films. - 1969. - Vol. 3. - iss. 1. - P. 3-12. DOI: https://doi.org/10.1016/0040-6090(69)90107-2

65. Yu, Y.-T. Evaluation of residual stresses in thin films by critical buckling observation of circular microstructures and finite element method / Y.-T. Yu, W.-Z. Yuan, D.-Y. Qiao, Q. Liang // Thin Solid Films. - 2008. - Vol. 516. - iss. 12. P. 4070-4075. DOI: https://doi.org/10.1016/j.tsf.2007.12.153

66. Blackburn, $\mathrm{H}$. The development of stress and surface temperature during deposition of lithium fluoride films / H. Blackburn, D.Campbell // Philosophical Magazine. - 1963. - Vol. 8. - iss. 89. - P. 823-831. DOl: https://doi.org/10.1080/14786436308213839

67. Story, H. Stress Annealing in Vacuum Deposited Copper Films / H. Story, R. Hoffman // Proceedings of the Physical Society. Section B. - 1957. - Vol. 70. iss. 10. - P. 950.

68. Priest, J. Stress anisotropy in silicon oxide films / J. Priest, H. Caswell, Y. Budo // Journal of Applied Physics. - 1963. - Vol. 34. - iss. 2. - P. 347-351. DOI: https://doi.org/10.1063/1.1702611

69. Priest, J. R. Apparatus for the Measurement of Stress in Vacuum Evaporated Films / J. R. Priest // Review of Scientific Instruments. - 1961. - Vol. 32. - iss. 12. - P. 1349-1351. DOI: https://doi.org/10.1063/1.1717249

70. Prevey, P. S. X-ray diffraction residual stress techniques / P. S. Prevéy, D. J. Hornbach. - ASM International, ASM Handbook. - 1986. - Vol. 10. - P. 380392. DOI: https://doi.org/10.31399/asm.hb.v10.a0006632

Надійшла до редакції 20.04.2021, розглянута на редколегії 20.04.2021

\section{Analysis of existing models of stress in thin films and coatings}

The analysis of existing models of stress in thin films and coatings was carried out. While reaching critical value, stress can lead to defects, cracks, delamination of coating from substrate, etc. The task of prediction and controlling of the direction and magnitude of the stress of coating-substrate system is relevant nowadays regardless of coating and thin films deposition methods. Different types of coatings and thin films are widely used in almost all industries: optics, mechanical engineering, measuring 
technology, medicine, micro- and nanoelectronics, etc. Development and investigation of new promising methods for the formation of nanostructures, such as nanowires in a plasma environment, requires a sufficient theoretical basis for the origin and growing of stresses. Depending on the mechanism, the causes of stress in thin films and coatings can be: chemical reactions, phase transformations, inclusions and impurities, particle bombardment (the cause of internal stress during coating growing); temperature changes (the cause of thermal stress due to different values of coefficients of thermal expansion of coating and substrate materials); deformation of coating-substrate system, etc. Models of stress development in coatings and thin films can be divided into the following groups: stress that occur at the coatingsubstrate interface, internal coating stress, and stress at the coating-environment interface. The study presents methods of stress measuring in thin films and coatings. Based on the results of the current research, it can be concluded that the existing models of stress in the process of growth of coatings and films, as well as stress arising under the action of external forces, describe only the causes of the stress and unfortunately do not give an understanding of their complex effect on stress-strain state of coating-substrate system and need further development and improvement. Stress relaxation is also important to obtain new structures and certain properties of coatings. The development of stress management tools can be considered as one of the ways to increase the lifetime of products with coatings and thin films.

Keywords: stress-strain state, stress, nanotechnology, thin films and coatings, destruction of coatings

\section{Відомості про автора:}

Шорінов Олександр Володимирович - кандидат технічних наук, старший викладач кафедри технології виробництва авіаційних двигунів, Національний аерокосмічний університет ім. М. Є. Жуковського «Харківський авіаційний інститут», м. Харків, Україна; o.shorinov@khai.edu; ResearchGate: Oleksandr-Shorinov; ORCID: 0000-0002-5057-6679

\section{About the Author:}

Shorinov Oleksandr Volodymyrovych - Candidate of Technical Sciences, Senior Lecturer of Department of Aircraft Engine Manufacturing Technology, National Aerospace University "Kharkiv Aviation Institute", Kharkiv, Ukraine; o.shorinov@khai.edu; ResearchGate: Oleksandr-Shorinov; ORCID: 0000-00025057-6679 